\title{
Detoxification of parthenium (Parthenium hysterophorus) and its metamorphosis into an organic fertilizer and biopesticide
}

\author{
Naseer Hussain ${ }^{1}$, Tasneem Abbasi ${ }^{1,2}$ and Shahid Abbas Abbasi ${ }^{1 *}$
}

\begin{abstract}
Background: Vermicompost of the toxic and allelopathic weed parthenium (Parthenium hysterophorus) was explored for its possible use as an organic fertilizer. Replicated plant growth trials were conducted using four levels of parthenium vermicompost $(0,2.5,3.75$, and $5 \mathrm{t} / \mathrm{ha}$ ) to assess their effects on the germination, growth, and fruition of a typical food plant ladies finger (Abelmoschus esculentus). Additionally the role of vermicompost in reducing plant pests and disease was evaluated.

Results: Vermicompost encouraged the germination and growth of ladies finger at all levels of vermicompost application, with best results obtained in $5 \mathrm{t} / \mathrm{ha}$ treatments. The positive impact extended up to the fruit yield. Vermicompost application also improved the quality of fruits in terms of mineral, protein, and carbohydrate contents, and reduced the disease incidence and pest attacks.

Conclusions: The studies establish the fact that parthenium acquires all the qualities of a good organic fertilizer with concomitant loss of its toxic and allelopathic properties after it gets vermicomposted. The findings raise the prospects of economical and eco-friendly utilization of billions of tons of parthenium biomass which is generated annually but goes to waste at present.
\end{abstract}

Keywords: Invasive weed, Allelopathy, Organic fertilizer, Biopesticide, Vermicomposting

\section{Background}

Parthenium hysterophorus, commonly called as congress grass, is among the world's seven most noxious and devastating weeds (Patel 2011). It is an annual flowering, erect, and severally branched ubiquitous herb, which grows aggressively in a wide range of habitats (Akter and Zuberi 2009). Due to the absence of any effective natural enemies and due to its allelopathic nature, large seed bank, and fast growth rate, parthenium grows luxuriantly all through the year, infesting millions of hectares of land masses including agricultural fields, parks, orchards, railway tracks, and other open areas (Wiesner et al. 2007; Nigatu et al. 2010; Qureshi

\footnotetext{
*Correspondence: abbasi.cpee@gmail.com; prof.s.a.abbasi@gmail.com ${ }^{1}$ Centre for Pollution Control \& Environmental Engineering, Pondicherry University, Chinakalapet, Puducherry 605 014, India

Full list of author information is available at the end of the article
}

et al. 2014). This proves disastrous in terms of monopolizing of space and nutrients by parthenium at the expense of other vegetation, consequent loss of biodiversity, and associated ecological imbalances (Hussain et al. 2016a, b). Parthenium's dominance over other vegetation is fostered by the presence of allelopathic compounds in parthenium, especially parthenin, hysterin, ambrosin, and flavonoids (Maishi et al. 1998; Khan and Abbasi 1998; Knox et al. 2011; Patel 2011; Kaur et al. 2014). These compounds are leached when dew or rain falls on parthenium (Abbasi and Abbasi 2011), and reach the underlying soil. There they cause toxicity, discouraging the growth of other vegetation in the vicinity of parthenium, thereby aiding and abetting the spread of parthenium monocultures (Hussain et al. 2016a, b).

Parthenium has mammalian toxicity as well. It causes dermatitis, eczema, asthma, allergic rhinitis, hay fever, 
black spots, burning, and blisters around eyes in mammals, including humans (Gunaseelan 1987; Towers and Rao 1992; Maishi et al. 1998; Morin et al. 2009; Akhtar et al. 2010). Exposure to parthenium also causes systemic toxicity including loss of skin pigmentation, dermatitis, diarrhea, and degenerative changes in liver and kidneys in livestock who accidentally graze upon parthenium (Gunaseelan 1987; Rajkumar et al. 1988; Lakshmi and Srinivas 2007).

The eradication of parthenium is a major challenge, primarily because of its epidemic proliferation, strong reproductive potential, hardiness, and competitiveness, apart from its wide ecological adoptability. Efforts made across the world to find persistent methods of controlling parthenium by way of mechanical, chemical, or biological means, have at best achieved only partial and temporary success (Manoj 2014; Hussain et al. 2016a). The weed has never been eradicated from any country and its spread in all the tropical and sub-tropical regions of the world is only increasing with time. When viewed as a resource, for the generation of green manure, biogas production, biopesticides, and drugs (Abbasi et al. 1990; Kishor et al. 2010; Kumar et al. 2012; Gunaseelan 1987; Patel 2011; Tauseef et al. 2013; Singh and Garg 2014; Kumar et al. 2014; Anwar et al. 2015; Hussain et al. 2016b), parthenium has proved uneconomical, expensive, and unsustainable. Thus finding an ecologically sound and economically viable means by which parthenium can be gainfully utilized in large quantities appears to be the only recourse which can make it profitable to regularly harvest the weed, thereby keeping it under some control.

One such option is conversion of parthenium biomass into organic fertilizer through vermicomposting. When a substrate is vermicomposted, it converts the latter into fine peat-like material and transforms some of its nutrients into more bioavailable forms (Hussain et al. 2015, 2016a, b. The vermicompost acquires several species of microflora, besides hormones and enzymes as it passes though the earthworms' gut (Pramanik et al. 2007; Ievinsh 2011). Past studies have reported that vermicompost derived from animal manure stimulated seed germination (Atiyeh et al. 2000; Zaller 2007; Lazcano et al. 2010), enhanced plant growth (Edwards Clive 2004; Lazcano et al. 2009; Samrot et al. 2015), and the yield and the quality of fruits (Singh et al. 2008; Doan et al. 2015) of several plant species. They are also believed to induce resistance in plants against pests and disease (Yardim et al. 2006; Edwards et al. 2010; Serfoji et al. 2010; Carr and Nelson 2014). But it is not yet established whether vermicompost derived from plants, more so from toxic and allelopathic plants like parthenium, can be as benign and effective an organic fertilizer as manure-derived vermicomposts are. In our recent studies (Gajalakshmi and Abbasi 2002; Hussain et al. 2016a, b) it was seen that soil augmented with parthenium vermicompost had enabled better germination success of four species of food plants compared to the control soil. But will the beneficial effect extend to plant growth, fruit yield, and quality of the fruit? Will the parthenium vermicompost also help the fertilized plants to repel pathogens the way manure-derived vermicomposts are known to do? In order to find definite answers to these questions, the present field-scale study has been carried out on the effect of parthenium vermicompost on a common vegetable ladies finger (Abelmoschus esculentus) from germination stage right up to the quality and yield of fruit.

\section{Experimental}

The experiment was carried out at the Pondicherry University, Puducherry, India, which is located along the eastern coast of the South India $\left(11^{\circ} 56^{\prime} \mathrm{N}, 79^{\circ} 53^{\prime} \mathrm{E}\right)$. This region experiences hot summers, with maximum day temperature $35-38{ }^{\circ} \mathrm{C}$, during March-July and mild winters during December-February (maximum day temperature $29-32{ }^{\circ} \mathrm{C}$ ). The average annual rainfall is about $1300 \mathrm{~mm}$, concentrated mainly during October-December but with a few rainy days occurring in July-August and January as well. The study was conducted during February-May which is ideal for growing ladies finger in the study area (ICAR 2011). The vermicompost used in the experiment was produced from parthenium leaves, which were collected from the vicinity of Pondicherry University campus. The leaves were washed to remove the adhering soil and subjected to the earthworm species Eisenia foetida in pulse-fed, high-rate vermireactors, as detailed by NayeemShah (2014), and Nayeem-Shah et al. (2015). There was no pre-composting or any manure supplementation. The vermicast was periodically harvested in each pulse and this precisely quantifiable product of the earthworm action was deemed as vermicompost (Abbasi et al. 2009, 2015). The characteristics of the vermicompost are detailed earlier by Hussain et al. (2016a, b).

To study the effect of parthenium vermicompost on several stages of plant growth, an outdoor experiment was conducted using low-density polyethylene (LDPE) bags of 50-1 capacity as containers of the soil. In separate treatments, vermicompost was supplemented in bags to the extent of $0,2.5,3.75$, and $5 \mathrm{t} / \mathrm{ha}$. For each treatment 35 bags were set and in each bag 5 ladies finger (Abelmoschus esculentus) seeds were sown. Soil used in the study was not used for cultivation in the past and had not received any anthropogenic input of fertilizers. Germination success was assessed up to 8 days and has been presented as germination percentage. After recording the germination success, seedlings in each bag were thinned to single while discarding the other four.

The growth experiment with daily monitoring was continued for 15 weeks, during which all the bags were irrigated with tap water. After 100 days of growth, five 
plants from each treatment were randomly harvested for the determination of shoot length, root length, plant biomass, number of leaves, stem diameter, and number of branches. The harvested plants were washed with tap water to remove the soil adhering to their roots, wiped, and weighed. They were then oven dried at $105{ }^{\circ} \mathrm{C}$ to a constant weight, to calculate their dry weight. Flowering was assessed in terms of number of days to the appearance of the first flower, and the total flowers emerging per plant. The fruits (pods) were harvested at each alternative days and the yield was assessed in terms of number and weight of pods harvested per plant. Further the average length $(\mathrm{cm})$ and diameter $(\mathrm{mm})$ of the pods were also recorded. The chlorophyll and carotenoid contents of the leaves were estimated by following the procedure of Moran and Porath (1980) using N, N-dimethyl formamide (DMF) as an extractant. The optical density of the extract was read at 470,647, and $664 \mathrm{~nm}$ in a UV-Visible spectrophotometer, and the concentration of pigments was determined as detailed by Wellburn (1994). The fruits (pods) of the ladies finger were analyzed for protein, carbohydrate, and mineral content by Kjeldahl, Anthrone, and dry ashing methods, respectively (Nielsen 2010). The total solid content was determined by heating the pods at $105^{\circ} \mathrm{C}$ to a constant weight.

In the course of the experiment the plants were infested with leaf miners and leaf spot disease. The leaf miner infection, traced to Liriomyza spp. was seen in the symptoms of feeding punctures and leaf mines appearing as white speckles on the upper leaf surface (Ahmed 2000). Plants were considered infected by the fungus, Alternaria alternate when there were light brown spots on leaves, which later turned into concentric dark brown spots (Cho and Moon 1980; Werner 1987; Tohyama et al. 2005; Arain et al. 2012). When the intensity of the infection was particularly severe, the infected leaves become brown, eventually dying and falling off (Canihos et al. 1999; Amenduini et al. 2003; Antonijevic et al. 2007). There was also borer infestation in the fruits due to the Earias vittella (Sharma et al. 2010; Halder et al. 2015); it was quantified as weight percentage of the infected fruits to the total weight of fruits per treatment.

The data were statistically analyzed for assessing the extent of significance in the observed variations-especially by one-way analysis of variance and least significant difference (LSD) - as per standardized protocols (Alan and David 2001; Field 2009).

\section{Results and discussion}

The substitution of the soil with parthenium vermicompost enabled significantly greater germination success of ladies finger seeds in comparison to controls (Table 1). In comparison with the controls (62.29\%), a germination success of $85.71 \%$ was achieved with vermicompost treatment $5 \mathrm{t} /$ ha followed by 81.71 and $77.14 \%$ with 3.75 and $2.5 \mathrm{t} / \mathrm{ha}$, respectively. The increase in seed germination in vermicompost-amended soils may be due to the increased concentrations of nitrate and ammonium in them, relative to the control soils. It is now beyond the dispute that nitrate and ammonium are efficient breakers of seed dormancy, facilitating germination (Bewley and Black 1982; Hilhorst and Karssen 2000). In recent studies, Hussain et al. 2016a reported that parthenium vermicompost significantly enhanced the relative concentrations of nitrate and ammonium in soil compared with the controls.

There was also better growth of ladies finger in terms of all the variables studied compared with the controls (Table 1). An increase in growth was observed with increasing concentration of vermicompost in the soil, the trend being control $<2.5<3.75<5 \mathrm{t} / \mathrm{ha}$. The growth of ladies finger had shown significant enhancement even with a relatively small concentration of parthenium vermicompost $(2.5 \mathrm{t} / \mathrm{ha})$ in the container medium. Maximum shoot length $122.6 \pm 10.21 \mathrm{~cm}$, root length $53.0 \pm 5.24 \mathrm{~cm}$, shoot diameter $13.38 \pm 1.30 \mathrm{~mm}$, shoot dry weight $30.67 \pm 3.06 \mathrm{~g}$, root dry weight $9.38 \pm 0.93 \mathrm{~g}$, number of leaves $30.6 \pm 2.97$, and number of branches $5.2 \pm 0.84$ were recorded in plants grown in soil amended with $5 \mathrm{t} / \mathrm{ha} \mathrm{VC}$ treatments. Parthenium vermicompost also induced early flowering and significantly higher number of flowers in ladies finger plants, in comparison to controls. The yield, in terms of number and weight of pods per plant, and the length and diameter of the pods, was also significantly higher in VC treatments than the controls (Fig. 1). Past studies have demonstrated that vermicompost derived from animal manure increased the growth and yield of several plant species (Doan et al. 2013; Joshi et al. 2015; Ayyobi et al. 2014; Xu et al. 2014; Akhzari et al. 2015; Kumar et al. 2015; Saxena et al. 2015).

Vermicompost derived from different substrates especially from animal manures are known to contain all the necessary plant nutrients in more bioavailable form than is present in the parent substrate (Edwards et al. 2011). It also contains diverse microflora, which are beneficial for soil health and the plant growth. A number of studies also reported the presence of plant growth regulators especially humic and fulvic acids, and phytohormones in manure-based vermicompost (Muscolo et al. 1999; Atiyeh et al. 2000, 2001, 2002; Arancon et al. 2005, 2008; Ievinsh 2011). It is the combined action of bioavailable nutrients, plant growth regulators, and soil microflora in the vermicompost that is responsible for enhancing the plant growth and yield (Chan and Griffiths 1988; Edwards and Burrows 1988; Wilson and Carlile 1989; Atiyeh et al. 1999; Ayyobi et al. 2014; Xu 
Table 1 Seed germination, plant growth, flowering, and disease incidence in ladies finger plants grown in soil fortified with different concentrations of parthenium vermicompost

\begin{tabular}{|c|c|c|c|c|c|}
\hline \multirow[t]{2}{*}{ Parameters, average value } & \multicolumn{4}{|c|}{ Vermicompost concentration } & \multirow[t]{2}{*}{$F$ value } \\
\hline & $0 \mathrm{t} / \mathrm{ha}$ (control) & $2.5 \mathrm{t} / \mathrm{ha}$ & $3.75 \mathrm{t} / \mathrm{ha}$ & $5 \mathrm{t} / \mathrm{ha}$ & \\
\hline \multicolumn{6}{|l|}{ Germination } \\
\hline Germination percentage & $62.29 \pm 6.46^{a}$ & $77.14 \pm 7.10^{b}$ & $81.71 \pm 7.47^{c}$ & $85.71 \pm 9.17^{d}$ & $63.253^{*}$ \\
\hline \multicolumn{6}{|l|}{ Growth } \\
\hline Shoot length $(\mathrm{cm})$ & $23.6 \pm 2.97^{\mathrm{a}}$ & $86.0 \pm 6.86^{b}$ & $98.8 \pm 7.98^{c}$ & $122.6 \pm 10.21^{d}$ & $159.515^{*}$ \\
\hline Root length (cm) & $34.4 \pm 3.21^{\mathrm{a}}$ & $41.4 \pm 3.85^{b c}$ & $46.0 \pm 4.58^{c}$ & $53.0 \pm 5.24^{d}$ & $16.627^{*}$ \\
\hline Shoot diameter (mm) & $4.48 \pm 0.38^{\mathrm{a}}$ & $10.22 \pm 1.00^{b c}$ & $10.78 \pm 0.89^{c}$ & $13.38 \pm 1.30^{d}$ & $77.381^{*}$ \\
\hline Shoot dry weight (g) & $1.96 \pm 0.31^{\mathrm{a}}$ & $17.26 \pm 0.83^{b}$ & $26.00 \pm 2.48^{c}$ & $30.67 \pm 3.06^{d}$ & $195.511^{*}$ \\
\hline Root dry weight (g) & $1.39 \pm 0.13^{\mathrm{a}}$ & $4.94 \pm 0.47^{b}$ & $6.12 \pm 0.59^{c}$ & $9.38 \pm 0.93^{d}$ & $149.649^{*}$ \\
\hline No of leaves & $11.8 \pm 1.10^{\mathrm{a}}$ & $24.8 \pm 2.49^{b}$ & $28.4 \pm 2.41^{\mathrm{cd}}$ & $30.6 \pm 2.97^{d}$ & $64.352^{*}$ \\
\hline No of branches & $0.0 \pm 0.00^{\mathrm{a}}$ & $2.4 \pm 0.55^{b}$ & $4.4 \pm 0.89^{c d}$ & $5.2 \pm 0.84^{d}$ & $59.852^{*}$ \\
\hline \multicolumn{6}{|l|}{ Flowering } \\
\hline Days to first flowering & $52.70 \pm 4.85^{\mathrm{a}}$ & $41.00 \pm 2.91^{b c}$ & $39.10 \pm 3.31^{\mathrm{cd}}$ & $36.80 \pm 1.93^{\mathrm{d}}$ & $42.882^{*}$ \\
\hline Number of flowers per plant & $2.90 \pm 0.32^{\mathrm{a}}$ & $7.80 \pm 1.14^{b}$ & $11.80 \pm 1.14^{c}$ & $12.90 \pm 0.99^{d}$ & $224.036^{*}$ \\
\hline \multicolumn{6}{|l|}{ Diseases incidence } \\
\hline Diseases incidence percentage & $21.43 \pm 4.95^{\mathrm{a}}$ & $13.57 \pm 4.29^{\mathrm{bcd}}$ & $12.14 \pm 4.88^{\mathrm{cd}}$ & $12.14 \pm 6.34^{d}$ & $2.976^{n}$ \\
\hline
\end{tabular}

et al. 2014; Akhzari et al. 2015; Kumar et al. 2015; Saxena et al. 2015). In the present study we suggest that parthenium vermicompost may have also imbibed with similar attributes to that of the manure-based vermicomposts that has resulted in greater germination success, better plant growth, and yield of ladies finger plants. Recently (Hussain et al. 2016a, b) have reported that parthenium vermicompost contains a number of fatty acids, alcohols, alkanes, alkenes, and nitrogenous compounds in it and enhanced the microbial biomass carbon of the soil. Beside these factors, parthenium vermicompost, as like manure-based vermicomposts, is also known to induce positive impact on soil physical properties and hence may also have contributed to the better plant growth (Hussain et al. 2016a).
The levels of pigments in the leaves of the ladies finger plants were significantly influenced by the vermicompost application (Table 2). Maximum chlorophyll $(1.43 \pm 0.09 \mathrm{mg} / \mathrm{g})$ and carotenoid $(0.90 \pm 0.07 \mathrm{mg} / \mathrm{g})$ content was recorded in $5 \mathrm{t} /$ ha vermicompost treatments. The total solids and ash (mineral) content of vermicomposttreated plants were also significantly higher compared to the controls. An increase in the protein and carbohydrate concentrations were also recorded in the plants grown in vermicompost-amended soils (Fig. 2). All these gains are perhaps due to the greater bioavailability of nutrients in vermicompost treatments compared to the controls, as has been earlier seen with manure-based vermicompost (Abduli et al. 2013; Ayyobi et al. 2014; Akhzari et al. 2015; Yadav et al. 2015).

Table 2 Chlorophyll and carotenoid content of ladies finger plants grown in soil fortified with different concentrations of parthenium vermicompost

\begin{tabular}{|c|c|c|c|c|c|}
\hline \multirow[t]{2}{*}{ Parameters, average value } & \multicolumn{4}{|c|}{ Vermicompost concentration } & \multirow[t]{2}{*}{$F$ value } \\
\hline & $0 \mathrm{t} / \mathrm{ha}$ (control) & $2.5 \mathrm{t} / \mathrm{ha}$ & 3.75 t/ha & $5 \mathrm{t} / \mathrm{ha}$ & \\
\hline Chlorophyll 'a' (mg/g) & $0.47 \pm 0.04^{\mathrm{a}}$ & $0.62 \pm 0.04^{b c}$ & $0.63 \pm 0.04^{c}$ & $0.91 \pm 0.07^{d}$ & $68.604^{*}$ \\
\hline Chlorophyll 'b' (mg/g) & $0.25 \pm 0.02^{\mathrm{ac}}$ & $0.29 \pm 0.02^{b c}$ & $0.26 \pm 0.01^{c}$ & $0.52 \pm 0.04^{d}$ & $120.380^{*}$ \\
\hline Total Chlorophyll (mg/g) & $0.72 \pm 0.04^{\mathrm{a}}$ & $0.90 \pm 0.03^{b c}$ & $0.89 \pm 0.04^{c}$ & $1.43 \pm 0.09^{d}$ & $149.604^{*}$ \\
\hline Carotenoid (mg/g) & $0.30 \pm 0.03^{\mathrm{a}}$ & $0.43 \pm 0.04^{b c}$ & $0.40 \pm 0.04^{c}$ & $0.90 \pm 0.07^{d}$ & $154.545^{*}$ \\
\hline
\end{tabular}

Results which do not differ significantly (LSD test; $p<0.05$ ) carry at least one character in the superscript which is common ${ }^{*} p<0$ 
Parthenium vermicompost was effective in inducing resistance in the ladies finger plants against pests and pathogens. A significant reduction in the infestation of leaf miners, leaf spot disease, and fruit borers was observed (Table 1; Fig. 1E), the trend being $0 \mathrm{t} / \mathrm{ha}$ (control) $>2.5>3.75>5 \mathrm{t} / \mathrm{ha}$. At the early stages of growth the seedlings were seen severely infested by leaf liner; however, as the growth increased the number of incidents decreased in proportion. Previous studies have reported that plants grown in soil amended with manure-based vermicompost have shown a reduction in the pest and disease attack (Edwards et al. 2010; Cardoza and Buhler
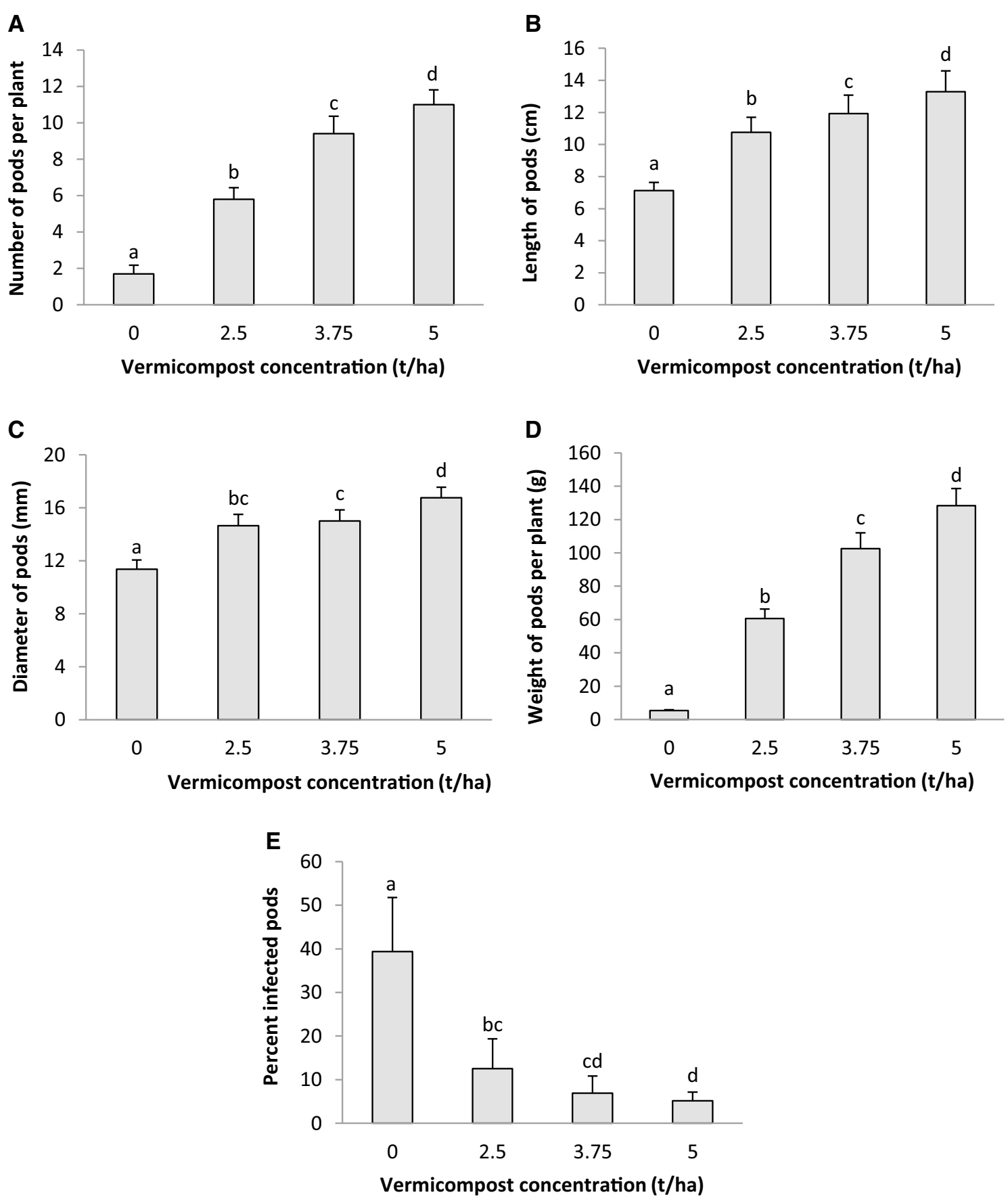

Fig. 1 Effect of parthenium vermicompost on $\mathbf{A}$ number of pods, B length of pods, C diameter of pods, D weight of pods per plant, and $\mathbf{E}$ weight of infected pods of ladies finger. The standard deviation is indicated on the chart. Results which do not differ significantly (LSD test; $p<0.05)$ carry at least one character in the superscript which is common 
2012). Different authors have provided different explanations for the pesticidal properties of the vermicompost which basically revolve around two conjectures: better nutrient availability hence greater vitality in warding off infection, and presence of pathogen-destroying microorganisms (Arancon et al. 2005; 2008; Yardim et al. 2006; Cardoza 2011; Singh et al. 2013; Xiao et al. 2016). The present studies indicate that the vermicompost of parthenium is also imbibed with a similar attribute. Past studies on manure-based vermicompost have indicated that better nutrient availability and presence of antimicrobial compounds such as flavonoids, phenolics, and humic acids in the vermicompost may have induced the resistance to pathogens in the plants (Graham and Webb 1991; Hill et al. 1999; Haviola et al. 2007; Sahni et al. 2008; Edwards et al. 2010). Similarly beneficial attributes seem to be present in parthenium's vermicompost as well.

\section{Conclusion}

In a field study, effect of vermicompost produced solely from an allelopathic weed parthenium has been investigated on germination, growth, yield, and quality of ladies finger (Abelmoschus esculentus). The effect of the vermicompost in inducing resistance in ladies finger against disease was also assessed. In general vermicompost application increased germination success, plant growth, and yield-the positive effect increased in prominence as the extent of vermicompost application was enhanced from 2.5 to $5 \mathrm{t} / \mathrm{ha}$. Parthenium vermicompost also induced beneficial changes in the biochemical and mineral content of the ladies finger. Additionally, ipomoea vermicompost induced resistance in ladies finger towards disease and pest attacks. Overall, contrary to the toxic and allelopathic nature of parthenium, its vermicompost manifests the attributes of highly plant-friendly organic fertilizer that vermicomposts derived from animal manure are known to possess.
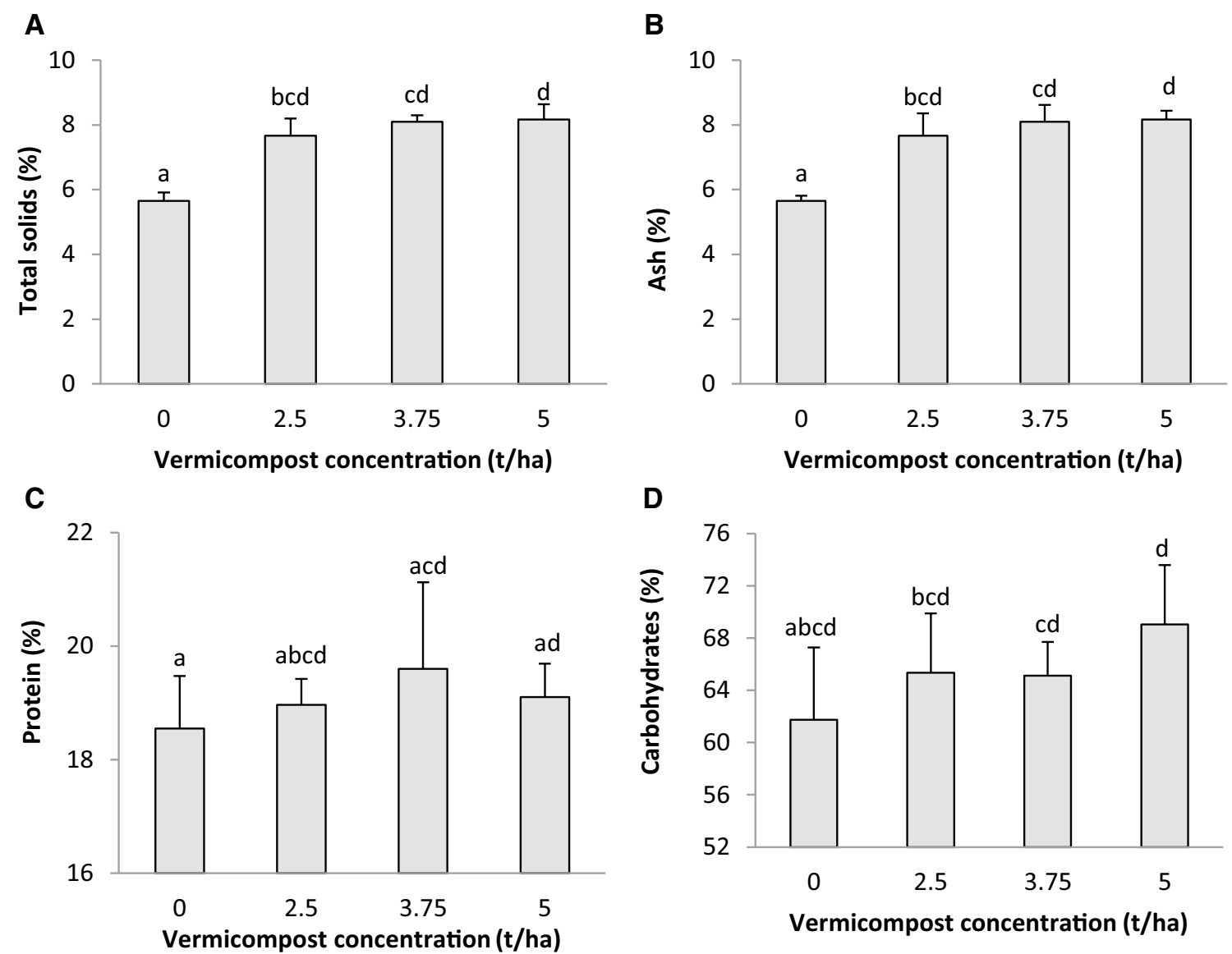

Fig. 2 Effect of parthenium vermicompost on $\mathbf{A}$ totals solids, B ash content, $\mathbf{C}$ protein content, and $\mathbf{D}$ carbohydrate content of ladies finger pods. The standard deviation is indicated on the chart. Results which do not differ significantly (LSD test; $p<0.05$ ) carry at least one character in the superscript which is common 


\section{Authors' contributions}

The experiments were planned and designed by NH, TA, and SAA who also jointly interpreted the findings. The experiments were conducted by NH. All authors read and approved the final manuscript.

\section{Author details}

${ }^{1}$ Centre for Pollution Control \& Environmental Engineering, Pondicherry University, Chinakalapet, Puducherry 605 014, India. ${ }^{2}$ Department of Fire Protec tion Engineering, Worcester Polytechnic Institute, Worcester, MA 01609, USA.

\section{Acknowledgements}

Authors thank the University Gants Commission, New Delhi, for support.

\section{Competing interests}

The authors declare that they have no competing interests.

\section{Publisher's Note}

Springer Nature remains neutral with regard to jurisdictional claims in published maps and institutional affiliations.

Received: 31 March 2017 Accepted: 7 June 2017

Published online: 15 June 2017

\section{References}

Abbasi T, Abbasi SA (2011) Sources of pollution in rooftop rainwater harvesting systems and their control. Crit Rev Environ Sci Technol (Taylor and Francis) 41(23):2097-2167

Abbasi SA, Nipaney PC, Schaumberg GD (1990) Bioenergy potential of 8 common aquatic weeds. Biolo Wastes (Elsevier) 34(4):359-366

Abbasi T, Gajalakshmi S, Abbasi SA (2009) Towards modeling and design of vermicomposting systems: mechanisms of composting/vermicomposting and their implications. Indian J Biotechnol 8:177-182

Abbasi SA, Nayeem-Shah M, Abbasi T (2015) Vermicomposting of phytomass: limitations of the past approaches and the emerging directions. J Clean Prod 93:103-114

Abduli MA, Amiri L, Madadian E, Gitipour S, Sedighian S (2013) Efficiency of vermicompost on quantitative and qualitative growth of tomato plants. Int J Environ Res 7(2):467-472

Ahmed MMM (2000) Studies on the control of insect pests in vegetables (okra, tomato, and onion) in Sudan with special reference to neem-preparations Doctoral dissertation, University of Göttingen, Göttingen

Akhtar N, Satyam A, Anand V, Verma KK, Khatri R, Sharma A (2010) Dysregulation of $T_{H}$ type cytokines in the patients of Parthenium induced contact dermatitis. Clin Chimica Acta 411:2024-2028

Akhzari D, Attaeian B, Arami A, Mahmoodi F, Aslani F (2015) Effects of vermicompost and arbuscular mycorrhizal fungi on soil properties and growth of Medicago polymorpha L. Compos Sci Util 23(3):142-153

Akter A, Zuberi MI (2009) Invasive alien species in Northern Bangladesh: identification, inventory and impacts. Int J Biodivers Conserv 15:129-134

Alan Clewer G, David Scarisbrick H (2001) Practical statistics and experimental design for plant and crop sciences. Wiley, England

Amenduini M, D'Amico M, Colella C, Cirulli M (2003) Severe outbreaks of alternaria leaf spot on kiwi in Southern Italy. Ferguson-Basilicata 53:39-43

Antonijevic D, Fakultet P, Zemun B, Mitrovic P (2007) Leaf spot of oilseed rape Biljni lekar (Serbia). Plant Doctor 35:443-449

Anwar MF, Yadav D, Kapoor S, Chander J, Samim M (2015) Comparison of antibacterial activity of Ag nanoparticles synthesized from leaf extract of Parthenium hystrophorus $\mathrm{L}$ in aqueous media and gentamicin sulphate, In-vitro. Drug Dev Ind Pharm 41:43-50

Arain AR, Jiskani MM, Wagan KH, Khuhro SN, Khaskheli MI (2012) Incidence and chemical control of okra leaf spot disease. Pak J Bot 44(5):1769-1774

Arancon NQ, Galvis PA, Edwards CA (2005) Suppression of insect pest populations and damage to plants by vermicomposts. Bioresource Tech 96(10):1137-1142

Arancon NQ, Edwards CA, Babenko A, Cannon J, Galvis P, Metzger JD (2008) Influences of vermicomposts, produced by earthworms and microorganisms from cattle manure, food waste and paper waste, on the germination, growth and flowering of petunias in the greenhouse. Appl Soil Ecol 39(1):91-99

Atiyeh RM, Subler S, Edwards CA, Metzger J (1999) Growth of tomato plants in horticultural media amended with vermicompost. Pedobiologia 43:724-728

Atiyeh RM, Arancon N, Edwards CA, Metzger JD (2000) Influence of earthworm-processed pig manure on the growth and yield of greenhouse tomatoes. Biores Technol 75:175-180

Atiyeh RM, Edwards CA, Subler S, Metzger JD (2001) Pig manure vermicompost as a component of a horticultural bedding plant medium: effects on physicochemical properties and plant growth. Biores Technol 78:11-20

Atiyeh RM, Lee S, Edwards CA, Arancon NQ, Metzger JD (2002) The influence of humic acids derived from earthworms-processed organic wastes on plant growth. Biores Technol 84:7-14

Ayyobi H, Hassanpour E, Alaqemand S, Fathi S, Olfati JA, Peyvast G (2014) Vermicompost leachate and vermiwash enhance French dwarf bean yield. Int J Veg Sci 20(1):21-27

Bewley JD, Black M (1982) Physiology and biochemistry of seeds in relation to germination. Springer, Berlin

Canihos Y, Peever TL, Timmer LW (1999) Temperature, leaf wetness and isolate effects on infection of Minneola tangelo leaves by Alternaria sp. Plant Diseases 83(5):429-433

Cardoza YJ (2011) Arabidopsis thaliana resistance to insects, mediated by an earthworm-produced organic soil amendment. Pest Manag Sci 67(2):233-238

Cardoza YJ, Buhler WG (2012) Soil organic amendment impacts on corn resistance to Helicoverpa zea: Constitutive or induced?. Pedobiologia 55:343-347

Carr EA, Nelson EB (2014) Disease-suppressive vermicompost induces a shift in germination mode of Pythium aphanidermatum zoosporangia. Plant Dis 98:361-367

Chan PLS, Griffiths DA (1988) The vermicomposting of pre-treated pig manure Biol Wastes 24:57-69

Cho JT, Moon BJ (1980) The occurrence of strawberry black leaf spot caused by Alternaria alternata (Fr.) Keissler in Korea. Korean J Plant Prot 19(4):221-226

Doan TT, Ngo PT, Rumpel C, Nguyen BV, Jouquet P (2013) Interactions between compost, vermicompost and earthworms influence plant growth and yield: a 1 year greenhouse experiment. Sci Hortic 160:148-154

Doan TT, Henry-Des-Tureaux T, Rumpel C, Janeau J-L, Jouquet P (2015) Impact of compost, vermicompost and biochar on soil fertility, maize yield and soil erosion in Northern Vietnam: a 3 year mesocosm experiment. Sci Total Environ 514:147-154

Edwards CA, Burrows I (1988) The potential of earthworm composts as plant growth media. In: Edwards CA, Neuhauser E (eds) Earthworms in waste and environmental management. SPB Academic Press, The Hague, pp $21-32$

Edwards Clive A (2004) Earthworm ecology, 2nd edn. CRC Press, Washington

Edwards CA, Arancon NQ, Bennett MV, Askar A, Keeney G, Little B (2010) Suppression of green peach aphid (Myzus persicae) (Sulz.), citrus mealybug (Planococcus citri), and two spotted spider mite (Tetranychus urticae) (Koch.) attacks on tomatoes and cucumbers by aqueous extracts from vermicomposts. Crop Prot 29:80-93

Edwards CA, Norman QA, Sherman R (2011) Vermiculture technology, earthworms, organic waste and environmental management. CRC Press, Washington, pp 17-19

Field A (2009) Discovering statistics using SPSS. In SAGE Publications, London

Gajalakshmi S, Abbasi SA (2002) Effect of the application of water hyacinth compost/vermicompost on the growth and flowering of Crossandra undulaefolia, and on several vegetables. Bioresour Technol 85(2):197-199

Graham RD, Webb MJ (1991) Micronutrients and disease resistance and tolerance in plants. In: Mortvedt JJ, Cox FR, Shuman LM, Welch RM (eds) Micronutrients in agriculture, 2nd edn. Soil Science Society of America, Fitchburg, pp 329-370

Gunaseelan VN (1987) Parthenium as an additive with cattle manure in biogas production. Biol Wastes 21:195-202

Halder J, Sanwal SK, Rai AK, Rai AB, Singh B, Singh BK (2015) Role of physicomorphic and biochemical characters of different okra genotypes in relation to population of okra shoot and fruit borer, Earias vittella (Noctuidae: Lepidoptera). Indian J Agric Sci 85(2):278-282 
Haviola S, Kapari L, Ossipov V, Rantala MJ, Ruuhola T, Haukioja E (2007) Foliar phenolics are differently associated with Epirrata autumnata growth and immune competence. J Chem Ecol 33:1013-1023

Hilhorst HWM, Karssen CM (2000) Effect of chemical environment on seed germination. In: Fenner M (ed) Seeds: the ecology of regeneration in plant communities. CABI publishing, Wallingford, pp 293-310

Hill WJ, Clarke BB, Murphy JA (1999) Take-all suppression in creeping bentgrass with manganese and copper. Hortscience 34:891-892

Hussain N, Abbasi T, Abbasi SA (2015) Vermicomposting eliminates the toxicity of Lantana (Lantana camara) and turns it into a plant friendly organic fertilizer. J Hazard Mater 298:46-57

Hussain N, Abbasi T, Abbasi SA (2016a) Vermicomposting transforms allelopathic parthenium into a benign organic fertilizer. J Environ Manage 180:180-189

Hussain N, Abbasi T, Abbasi SA (2016b) Transformation of a highly pernicious and toxic weed parthenium into an eco-friendly organic fertilizer by vermicomposting. Int J Environ Stud 73:731-745

ICAR (2011) Handbook of agriculture. Indian Council of agricultural Research, Pusa

levinsh G (2011) Vermicompost treatment differentially affects seed germination, seedling growth and physiological status of vegetable crop species. Plant Growth Regul 65:169-181

Joshi R, Singh J, Vig AP (2015) Vermicompost as an effective organic fertilizer and biocontrol agent: effect on growth, yield and quality of plants. Rev Environ Sci Bio/Technol 14(1):137-159

Kaur M, Aggarwal NK, Kumar V, Dhiman R (2014) Effects and management of Parthenium hysterophorus: a weed of global significance, international scholarly research notices, p 1-12

Khan Fl, Abbasi SA (1998) Techniques and methodologies for risk analysis in chemical process industries. Discovery Publishing House, New Delhi

Kishor P, Maurya BR, Ghosh AK (2010) Use of uprooted Parthenium before flowering as compost: a way to reduce its hazards worldwide. Int I Soil Sci 5:73-81

Knox J, Jaggi D, Paul MS (2011) Population dynamics of Parthenium hysterophorus (Asteraceae) and its biological suppression through Cassia occidentalis (Caesalpiniaceae). Turk J Bot 35:111-119

Kumar A, Kumar A, Kumar V, Kumar M, Singh B, Cjouhan P (2012) Recycling of harmful weeds through NADEP composting. Vegetos 25:315-318

Kumar S, Pandey S, Pandey AK (2014) In vitro antibacterial, antioxidant, and cytotoxic activities of Parthenium hysterophorus and characterization of extracts by LC-MS analysis. Biomed Res Int 49:51-54

Kumar R, Singh MK, Kumar V, Verma RK, Kushwah JK, Pal M (2015) Effect of nutrient supplementation through organic sources on growth, yield and quality of coriander (Coriandrum sativum L.). Indian J Agric Res 49:278-281

Lakshmi C, Srinivas CR (2007) Parthenium: A wide angle view. Ind J Dermatol Venereol Leprol 73:296-306

Lazcano C, Arnold J, Tato A, Zalle JG, Domínguez J (2009) Compost and vermicompost as nursery pot components: effects on tomato plant growth and morphology. Span J Agric Res 7:944-951

Lazcano C, Sampedro L, Zas R, Domínguez J (2010) Assessment of plant growth promotion by vermicompost in different progenies of maritime pine (Pinus pinasterAit.). Compost Sci Util 18:111-118

Maishi Al, Ali PKS, Chaghtai SA, Khan GA (1998) A proving of Parthenium hysterophorus L. Br Homoeopath J 87:17-21

Manoj EM (2014) In vasive plants a threat to wild life, The Hindu, http://www. thehindu.com/news/national/kerala/invasive-plants-a-threat-to-wildlife/ article6432731.ece, p3

Moran R, Porath D (1980) Chlorophyll determination in intact tissues using N, $\mathrm{N}$-di-Methyl formamide. Plant Physiol 65:478-479

Morin L, Reid AM, Sims-Chilton NM, Buckley YM, Dhileepan K, Hastwell GT, Nordblom TL, Raghu S (2009) Review of approaches to evaluate the effectiveness of weed biological control agents. Biol Control 5:1-15

Muscolo A, Bovalo F, Gionfriddo F, Nardi F (1999) Earthworm humic matter produces auxin-like effects on Daucus carota cell growth and nitrate metabolism. Soil Biol Biochem 31:1303-1311

Nayeem-Shah M (2014) Exploration of methods for gainful utilization of phytomass-based biowaste, Ph.D. thesis, Pondicherry University, Kalapet, pp. 92

Nayeem-Shah M, Gajalakshmi S, Abbasi SA (2015) Direct, rapid and sustainable vermicomposting of the leaf litter of neem (Azadirachta indica). Appl Biochem Biotechnol 175:792-801
Nielsen SS (ed) (2010) Food analysis. Springer, New York, p 550

Nigatu L, Hassen A, Sharma J, Adkins SW (2010) Impact of Parthenium hysterophorus on grazing land communities in North-Eastern Ethiopia. Weed Biol Manag 10:143-152

Patel S (2011) Harmful and beneficial aspects of Parthenium hysterophorus: an update. 3 Biotech 1:1-9

Pramanik P, Ghosh GK, Ghosal PK, Banik P (2007) Changes in organic-C, N, $P$ and $K$ and enzyme activities in vermicompost of biodegradable organic wastes under liming and microbial inoculants. Biores Technol 98:2485-2494

Qureshi H, Arshad M, Bibi Y (2014) Invasive flora of Pakistan: a critical analysis. Int J Biosci 4:407-424

Rajkumar EDM, Kumar NVN, Haranm NVH, Ram NVS (1988) Antagonistic effect of $P$. hysterophorus on succinate dehydrogenase of sheep liver. J Environ Biol 9:231-237

Sahni S, Sarma BK, Singh DP, Singh HB, Singh KP (2008) Vermicompost enhances performance of plant growth-promoting rhizobacteria in Cicer arietinum rhizosphere against Sclerotium rolfsii. Crop Prot 27:369-376

Samrot AV, Vignesh MP, Vignesh V (2015) Utilization of vermicompost of organic waste for plant growth. Int J Pharm Bio Sci 6:B326-B332

Saxena J, Choudhary S, Pareek S, Choudhary AK, lquebal MA (2015) Recycling of organic waste through four different composts for disease suppression and growth enhancement in mung beans. Clean Soil Air Water 43:1066-1071

Serfoji P, Rajeshkumar S, Selvaraj T (2010) Management of root-knot nematode, Meloidogyne incognita on tomato cv Pusa Ruby by using vermicompost, AM fungus, Glomus aggregatum and mycorrhiza helper bacterium, Bacillus coagulans. J Agric Technol 6:37-45

Sharma RP, Swaminathan R, Bhati KK (2010) Seasonal incidence of fruit and shoot borer of okra along with climatic factors in Udaipur region of India. Asian J Agric Res 4(4):232-236

Singh RK, Garg Arti (2014) Parthenium hysterophorus L.- -neither noxious nor an obnoxious weed. Indian For 140:1260-1262

Singh R, Sharma RR, Kumar S, Gupta RK, Patil RT (2008) Vermicompost substitution influences growth, physiological disorders, fruit yield and quality of strawberry (Fragaria X ananassa Duch.). Biores Technol 99:8507-8511

Singh R, Singh R, Soni SK, Singh SP, Chauhan UK, Kalra A (2013) Vermicompost from biodegraded distillation waste improves soil properties and essential oil yield of Pogostemon cablin (patchouli) Benth. Appl Soil Ecol 70:48-56

Tauseef SM, Premalatha M, Tasneem Abbasi, Abbasi SA (2013) Methane capture from livestock manure. J Environ Manag 117:187-207

Tohyama A, Hayashi K, Taniguchi N, Naruse C, Ozawa Y, Shishiyama J, Tsuda M (2005) A new post-harvest disease of okra pods caused by Alternaria alternate. Ann Phytopathol Soc Jpn 61 (4):340-345

Towers GHN, Subba Rao PV (1992) Impact of the pantropical weed, Parthenium hysterophorus L. on human aff airs. In: Richardson RG (ed) Proceedings of the 1st international weed control congress Australia. Weed Sci Soc Victoria, Melbourne, pp 135-138

Wellburn AR (1994) The spectral determination of chlorophylls $a$ and b, as well as total carotenoids, using various solvents with spectrophotometers of different resolutions. J Plant Physiol 144:307-313

Werner M (1987) Necrotic leaf spot of apple caused by fungi of the genus Alternaria. Ochrona Roslin (Poland) 31:6-7

Wiesner M, Tessema T, Hoffmann A, Wilfried P, Buettner C, Mewis I, Ulrichs C (2007) Impact of the pan-tropical weed Parthenium hysterophorus L on human health in Ethiopia. Institute of Horticultural Science, Urban Horticulture

Wilson DP, Carlile WR (1989) Plant growth in potting media containingwormworked duck waste. Acta Hortic 238:205-220

Xiao Z, Liu M, Jiang L, Chen X, Griffiths BS, Li H, Hu F (2016) Vermicompost increases defense against root-knot nematode (Meloidogyne incognita) in tomato plants. Appl Soil Ecol 105:177-186

Xu Y, Wang C, Bi Y, Zhang Y, Cheng W, Sun Z, Zhang J, Lv Z, Guo X (2014) Influence of cow manure vermicompost soil mixtures on two flowers seedling cultivation. Acta Hort 1018:583-588

Yadav A, Suthar S, Garg VK (2015) Dynamics of microbiological parameters, enzymatic activities and worm biomass production during vermicomposting of effluent treatment plant sludge of bakery industry. Environ Sci Pollut Res 22(19):14702-14709 
Yardim EN, Arancon NQ, Edwards CA, Oliver TJ (2006) Suppression of tomato hornworm (Manduca quinquemaculata) and cucumber beetles (Acalymma vittatum and Diabotrica undecimpunctata) populations and damage by vermicomposts. Pedobiologia 50:23-29

Zaller JG (2007) Vermicompost as a substitute for peat in potting media: effects on germination, biomass allocation, yields and fruit quality of three tomato varieties. Sci Hortic 112:191-199
Gajalakshmi S, Abbasi SA, (2002) Effect of the application of water hyacinth compost/vermicompost on the growth and flowering of Crossandra undulaefolia, and on several vegetables. Bioresource Technology 85 (2):197-199. Tauseef SM, Premalatha M, Tasneem Abbasi, Abbasi SA, (2013) Methane capture from livestock manure. Journal of Environmental Management 117:187-207.

\section{Submit your manuscript to a SpringerOpen ${ }^{\circ}$ journal and benefit from:}

- Convenient online submission

- Rigorous peer review

- Open access: articles freely available online

- High visibility within the field

- Retaining the copyright to your article

Submit your next manuscript at $\boldsymbol{\nabla}$ springeropen.com 